\title{
A porta de palla ou a visión alternativa de Santiago de Compostela de Vicente Risco
}

A porta de palla or the alternative vision of Santiago de Compostela by Vicente Risco

\author{
Alba Rozas Arceo \\ Universidad de Salamanca, España \\ albarozas@usal.es
}

Recibido: 21/09/2021; Aceptado: 21/11/2021

\section{Resumo}

No presente estudo proponse que a novela $A$ porta de palla de Vicente Risco constitúe a recreación dunha historia alternativa baseada na construción de Nerbia como espazo contrafactual ou alternativo de Santiago de Compostela. Co propósito de corroborar esta hipótese, lévase a cabo a análise da novela desde os presupostos da cartografía literaria, que se fundamentan no suposto da existencia dunha interrelación entre o mundo empírico e os espazos ficcionais. Deste xeito, a partir das características narrativas de cada lugar, estabelécese unha serie de tipoloxías encamiñadas a dirimir as súas correspondencias coa xeografía real, atendendo ás súas posibilidades de representación cartográfica. Por último, conforme os mapas resultantes desta análise, que permite corroborar a suposición de partida, estúdase de que maneira a xestación do espazo alternativo trae consigo o desenvolvemento de novas premisas en torno á Historia.

Palavras chave: A porta de palla; cartografía literaria; espazo contrafactual; Santiago de Compostela.

\begin{abstract}
This study proposes that Vicente Risco's novel A porta de palla constitutes the recreation of an alternative history based on the construction of Nerbia as a counterfactual or alternative space of Santiago de Compostela. In order to corroborate this hypothesis, the novel is analysed from the assumptions of literary cartography, which are based on the supposition of the existence of an interrelation between the empirical world and fictional spaces. Thus, on the basis of the narrative characteristics of each place, a series of typologies are established to determine their correspondence with real geography, according to their cartographic representation possibilities. Finally, on the basis of the maps resulting from this analysis, which allow us to corroborate the initial assumption, we study how the gestation of the alternative space entails the development of new assumptions about History.
\end{abstract}

Keywords: A porta de palla; literary cartography; counterfactual space; Santiago de Compostela. 


\section{A PORTA DE PALLA UN EXERCICIO DE NARRATIVA EXPERIMENTAL DENTRO DO PANORAMA LITERARIO ESPAÑOL}

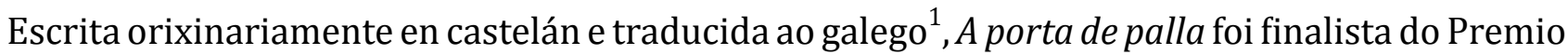
Nadal en 1952 con grande éxito da crítica e publicada pola Editorial Planeta ao ano seguinte ${ }^{2}$, na súa colección "Autores españoles contemporáneos" (Risco, 1981, p. 4) ${ }^{3}$. Dentro do panorama literario español no que se encadra, $A$ porta de palla sitúase a medio camiño entre o carácter experimental e metaliterario que predominou entre 1960 e 1970 e o realismo social característico das décadas anteriores. Trátase dunha novela de gran complexidade, non tanto diexética e argumental, como temática, temporal ${ }^{4}$ e espacial. A través dun narrador omnisciente, a obra recolle, entre outras tramas secundarias, o declive e remate do goberno de Baldonio de Strandia, bispo e conde da cidade de Nerbia. Malia o comportamento do seu dirixente, marcado pola corrupción política e económica, así como pola depravación moral, a cidade de Nerbia goza de prosperidade e boa reputación deontolóxica. Porén, tras a fuxida da concubina Rosinda e o cerco imposto polos seus inimigos políticos e relixiosos, Baldonio iniciará un camiño de purificación espiritual, físico e xeográfico. Este traxecto comeza no leito do protagonista, onde o abafan uns estraños soños que deixan pegada no seu corpo. Neles é arrastrado a Roma polo seu sobriño Finamor até se derrubar ante unha porta atoada con palla. Cando inicia a peregrinación á cidade de Roma, tamén guiado polo seu sobriño e acompañado por parte do pobo de Nerbia, vai procurar en realidade a restitución do seu poder. Non obstante, antes de traspasar os muros de Roma, alentado polo seu sobriño a un sincero arrepentimento, Baldonio rectifica a tempo de procurar nada máis a redención da alma. Unha vez obtido o perdón do santo pai, quen o destitúe dos seus cargos de conde e bispo a favor de Finamor, Baldonio retorna á cidade de Nerbia. Mais alí morre apedrado polos seus habitantes que o consideran o responsábel da decadencia política, económica e social, froito das revoltas producidas na súa ausencia. En relación co argumento, no tocante á temática, diferentes episodios e personaxes da novela -nomeadamente o ermitán Ascanio e Plutón Barrabás- serven para poñer de manifesto -en ocasións ex negativo- a ideoloxía católica, antimodernista e tradicionalista do propio Risco, así como a exaltación da irracionalidade, do misticismo, do ocultismo, do esoterismo, da maxia, da relixiosidade popular ou do espiritualismo relacionado coas tradicións orientais. Trátase de materias susceptíbeis dunha fonda análise crítica alén do presente estudo, posto que todas elas definen e están presentes no resto da produción do autor. Á luz destas consideracións, cómpre formularse unha pregunta chave: amais do argumento, cales son as particularidades que individualizan $A$ porta de palla fronte ás demais obras de Risco? A partir desta cuestión propoño unha hipótese e unha metodoloxía de análise axeitada para o seu estudo: a recreación dunha historia alternativa baseada na construción de Nerbia como espazo contrafactual desde os presupostos da cartografía literaria.

\section{UNHA VERSIÓN ALTERNATIVA DE SANTIAGO DE COMPOSTELA: A CIDADE DE NERBIA}

A concepción da linguaxe como instrumento válido para a representación da realidade sustenta

o establecemento da historiografía como disciplina académica a principios do século XIX. Non 
obstante, a posmodernidade, a través do chamado xiro lingüístico, reverte en boa medida este postulado ao defender que a linguaxe crea a realidade e non se limita a reproducila. Esta premisa entronca coas teorías sobre a escrita da Historia como acto de creación e imaxinación, que reconfigura os feitos pasados e mesmo o presente, en lugar de os reconstruír. A partir da consideración dos acontecementos históricos como ficción ${ }^{5}$, o foco de interese proxéctase sobre os ensaios de pensamento contrafactuais (Widmann, 2001, p. 170).

As historias contrafactuais constitúen, polo xeral, experimentos de caso que consisten na alteración dun fito histórico, ora propoñendo un desenlace diferente, ora mudando unha ou varias das situacións que deron lugar ao suceso en cuestión. Noutras palabras, alicérzanse en premisas que non se poden satisfacer. Máis polo miúdo, unha historia contrafactual baséase na relación do suposto ou antecedente $a$ coas implicacións do consecuente $b$. Antecedente e consecuente deben constituír expresións verbais, máis ou menos elaboradas, que respondan á estrutura lóxica seguinte: "se $a$, logo $b$ ". Ademais, no momento en que se formulen, cando menos, unha debe ser obviamente falsa con respecto a certo coñecemento. Polo tanto, as historias contrafactuais implican asumir unha premisa que se sabe claramente falsa e non presentan unha condición epistemolóxica incerta ou discutíbel (Albrecht e Danneberg, 2011, p. 14).

Aínda que implica un salto cara a unha irrealidade ontolóxica, a contrafactualidade non se define como un pasado imaxinario de libre invención, senón que se debe presentar como unha opción real no transcurso dos feitos históricos (Piatti e Hurni, 2009, p. 333). En consecuencia, os acontecementos históricos representan un requisito imprescindíbel para a produción de versións contrafactuais da Historia, tendo en conta que o afastamento con respecto aos primeiros debe ser deliberado (Widmann, 2011, p. 171). En definitiva, a contrafactualidade explora sucesos que puideron ser pero nunca foron, fronte aos efectivamente ocorridos (Piatti e Hurni, 2009, p. 339).

A meirande parte das historias contrafactuais responden ás características da ficción, pois a chave do xénero é a modificación da Historia. Nalgunhas ocasións, sitúanse ademais en localizacións espaciais remodeladas e reorganizadas e apóianse nunha corrente temporal alternativa (Piatti e Hurni, 2009, p. 333). Deste xeito, a contrafactualidade xérase a partir de espazos lixeiramente alleos á xeografía empírica, en certa medida recoñecíbeis, e o argumento proporciónalles aos lectores indicios sobre un pasado similar ao seu (Piatti e Hurni, 2009, pp. 339-40).

No caso de $A$ porta de palla, tentarei demostrar que o suposto ou antecedente $a$ que se sabe falso sería o desempeño por parte de Baldonio de Strandia dos cargos de conde e bispo da cidade de Nerbia, concibida como trasunto de Santiago de Compostela. Este antecedente é o que desencadea o resto de acontecementos narrados na novela. Non obstante, as distintas tramas da novela semellan unha opción posíbel no transcorrer dos feitos históricos relativos á cidade empírica, dado que o seu desenvolvemento está estreitamente ligado á institución política e relixiosa da Igrexa católica que representa, en calidade de xefe supremo, o papa de Roma.

Neste tipo de obras, os espazos chegan a ser o protagonista e, dadas as características anteriores, van desempeñar unha función crucial, pois os lugares contrafactuais poden ser narrados e mesmo cartografados. É dicir, pertencen á categoría da chamada ficción mapeábel, xa que representan un campo de análise interdisciplinar -histórico, literario, cartográfico e artístico- que induce á reflexión sobre a coexistencia e o solapamento de ficción e realidade. Non obstante, mentres a literatura contrafactual chegou a ser un xénero estabelecido, o estudo destes espazos e das súas características supón un territorio en boa medida inexplorado. 
Neste punto, entran en xogo as correlacións que se poden apuntar entre a cidade ficcional de Nerbia e o espazo empírico de Santiago de Compostela a partir de varios motivos espaciais. Estas correspondencias vanme permitir a consideración de Nerbia como un exemplo de ficción espacial, pois trátase dun lugar configurado artellando de xeito preciso un ámbito topográfico (Ficciones espaciales, Compostela geoliteraria, 2017).

O obxecto espacial predominante é o pazo do conde bispo de Nerbia, que tería como reflexo na realidade o Pazo de Xelmírez. Este lugar constitúe a residencia de Baldonio e centraliza a totalidade do seu poder político e relixioso, que se pon de manifesto desde as primeiras páxinas da novela, cando ten lugar a desaparición de Rosinda e o bispo cae enfermo. Primeiro os servos do pazo e, despois, por extensión, todos os habitantes de Nerbia fican en suspenso, pendentes da evolución do seu gobernante. Neste senso, cómpre sinalar que, tan pronto Baldonio abandona o acubillo do pazo na procura da concubina, desencadéase de xeito irremediábel o seu declive.

Outro espazo relevante na obra é a universidade, que atinxiría na xeografía empírica tanto á Facultade de Medicina, coma á de Filosofía e Letras, correspondentes na súa orixe aos actuais edificios do Pazo de Fonseca e da Facultade de Xeografía e Historia. 0 dobre vínculo pódese estabelecer atendendo ao papel que desenvolven os personaxes relacionados coa institución universitaria na obra, principalmente durante a convalecencia de Baldonio, cando varios físicos e cirurxiáns son chamados para curar o bispo. Os primeiros estabelecen entre eles e, máis adiante tamén con outros personaxes, debates de cariz metafísico á conta dos problemas do doente.

En terceira instancia, destaca a presenza da catedral de Nerbia, os seus elementos constituíntes e a súa contorna. 0 monumento sería a recreación ficcional da catedral de Santiago. Á catedral acode Baldonio, tras intentar matar o ermitán Ascanio e, desde unha das súas torres -presumibelmente a Berenguela, a máis elevada de todas, dada a súa función defensiva e, xa que logo, de miradoiro-, observa sete campamentos inimigos que asedian a cidade (Risco, 2020, p. 92). É o lugar onde, para evitar o fatal desenlace dunha guerra aberta e sen apoios contra os seus inimigos, finxe arrepentirse dos seus pecados coa esperanza de peregrinar a Roma para ser restituído polo sumo pontífice como conde e bispo de Nerbia. Amais, ao longo da novela alúdese a dúas prazas situadas derredor da catedral: "a gran Praza do Paraíso" (Risco, 2020, p. 95) e a "praza inmediata á do Paraíso" (Risco, 2020, p. 144). 0 primeiro destes espazos corresponderíase coa praza medieval de Santiago de Compostela, localizada entre o mosteiro de San Martiño Pinario e a porta norte da catedral, que supoñía o final do camiño de Santiago. Esta praza servía de adro da catedral e nela xuntábanse normalmente os comerciantes, tal como ocorre na novela. Recibía este nome á conta do ciclo da Xénese representado nesa fachada do monumento e, desde principios do século XVIII, foi anexionada á praza contigua da Inmaculada. Polo tanto, esta última representaría o potencial reflexo das dúas prazas indicadas na narración.

Do mesmo xeito, cómpre facer referencia a que Nerbia é unha cidade amurallada que conta con varias portas de entrada, en concreto sete, se atendemos ao número de campamentos responsábeis do primeiro intento de asedio, pois a cifra non se explicita na novela. En calquera caso, unha delas pode considerarse a "porta principal" (Risco, 2020, p. 228). No seu conxunto, muralla e portas, desempeñarán un papel fundamental cando, despois da marcha de Baldonio, se desencadeen diferentes revoltas entre campesiñado, nobreza e clero para acadar o goberno da cidade. Na xeografía empírica ou real, a antiga muralla de Santiago de Compostela coas súas sete portas -sendo a principal a do Camiño- poderían ser os referentes das de Nerbia.

Para rematar, dentro dos lindes da muralla de Nerbia sitúanse outros dous espazos con posíbeis reflexos no mundo empírico. Por unha banda, áchase o mosteiro onde encerran a fermosa Alda 
xunto con outras mulleres, protexidas de Baldonio. Por outra banda, sitúase a igrexa de Santa Walafrida á que acode o clérigo e poeta Hermanrico oír misa despois de cruzar onda os postos do mercado. 0 primeiro podería corresponderse, presuntamente, co mosteiro de San Paio de Antealtares, o único intramuros ocupado por monxas de clausura. 0 segundo podería ter como referente, talvez, a igrexa de Santa Susana, xa que o mercado de gando santiagués localizábase antigamente na Alameda.

De acordo con estas observacións, Risco presenta en A porta de palla unha xeografía cultural, cognitiva e histórica que se somete a unha deconstrución referencial. En particular, segundo a hipótese proposta, a novela pode entenderse fundamentalmente a partir do desenvolvemento dun espazo contrafactual. Deste xeito, as diferentes referencias espaciais de A porta de palla non van supoñer unha mera réplica da realidade, senón que van desempeñar un papel primordial.

A identificación entre xeografía empírica e ficcional que acabo de facer demostra que os eventos históricos posteriores no decurso da novela teñen un carácter contrafactual. Por este motivo, procederei á análise espacial da novela desde a cartografía literaria, disciplina que se fundamenta no suposto da existencia dunha interrelación entre o mundo empírico e os espazos literarios. Ao abeiro desta premisa, a elaboración de cartografías sobre o espazo contrafactual vai constituír un método xenuíno para o seu estudo, dado que as calidades xeométricas e pictóricas dos mapas contribúen a cumprir cos obxectivos de representación pertinentes.

\section{O ESPAZO CONTRAFACTUAL DE A PORTA DE PALLA: UNHA ANÁLISE METODOLÓXICA DESDE A CARTOGRAFÍA LITERARIA}

Tradicionalmente a cartografía literaria considérase unha subdisciplina da xeografía literaria. Non obstante, excede os límites deste estudo levar a cabo unha panorámica sobre a xestación e desenvolvemento da xeografía literaria como disciplina. A modo de recompilación sumarísima bastará mencionar, seguindo a Piatti (2008, pp. 67-68), que os termos "Literaturgeographie", "Literary Geography" e "géographie littéraire" xorden a principios do século XX nos territorios de fala xermana, inglesa e francesa respectivamente. Estas denominacións designaban orixinariamente a integración dunha metodoloxía xeográfica aos estudos de Teoría da Literatura para contrastar conceptos antropolóxicos ou psicanalíticos aplicados á análise literaria. Posteriormente, a xeografía literaria consolidouse como ciencia ao servizo da análise sistemática da Historia da Literatura a partir da súa división en dúas vertentes: por unha banda, a que ten como propósito dirimir as características rexionais da produción literaria de distintos territorios a partir do lugar de nacemento, residencial ou laboral dos escritores e, por outra banda, a que se dedica ao estudo dos territorios reais trasladados á literatura e aos espazos da ficción -ou creacións autoriais sen reflexo real específico. Agora ben, na práctica, o espazo vivencial dos autores é normalmente o espazo narrativo das súas ficcións, razón pola cal non se pode levar a cabo unha separación tallante entre ambas as tendencias analíticas. Por último, cabe sinalar que a designación "xeografía literaria" aglutina tanto perspectivas académicas como divulgativas, turísticas e didácticas -como guías de viaxe ou monografías de paisaxes literarias, por exemplo- que, en ocasións, proporcionan innovadoras percepcións da relación entre o contexto xeográfico e as obras literarias. En calquera caso, esta situación heteroxénea dificulta -e incluso imposibilita- a delimitación estrita dunhas liñas de investigación determinadas, marcadas por unha serie de regras que garantan un alto 
nivel cualitativo e metodolóxico de análise na disciplina, malia que ao seu heteroxéneo transfondo subxace a avaliación crítica dos distintos enfoques.

Á luz destes datos, o desenvolvemento da cartografía literaria xorde a raíz dun cambio de paradigma no estudo dos textos ficcionais -e non só-, que deixa de orbitar derredor do tempo para o facer en torno ao espazo. Esta concepción -catalogada como "topographical turn" (Weigel 2002, p. 158)- implica a consideración dos espazos literarios como elementos concretos e identificábeis xeograficamente, desde una perspectiva crítica, en lugar de meros topoi. En concreto, a cartografía literaria permite analizar o espazo ficcional a partir de representacións gráficas de rexións terrestres en escala reducida, incluíndo diferentes datos asociados a elas. A partir do mapeamento de contido ou de información concreta dun texto -ou dun conxunto de textos relacionados entre si-, permite levar a cabo análises de tipo estatístico, cuantitativo e cualitativo (Piatti e Hurni, 2011, p. 220). Estes estudos están orientados a proporcionar unha maior comprensión da ficción en xeral e do espazo literario en particular. Deste xeito, a cartografía literaria ofrece a posibilidade de estudar aspectos moi diversos relacionados coas obras ficcionais e o espazo.

Con todo, a concepción da cartografía literaria como disciplina ao servizo do mapeamento dos mundos de ficción e as súas particularidades específicas, vaime permitir estudar A porta de palla a partir do desenvolvemento dun espazo contrafactual, de acordo coa hipótese formulada.

Polo tanto, é no ámbito de estudo relativo á lóxica do espazo ficcional onde entra en xogo esta disciplina, a través de mapas que constitúen ferramentas para representar e examinar a xeografía específica da literatura en función da dialéctica do relato ficcional (Piatti, Bar, Reuschel, Hurni e Cartwright, 2009, p. 184). Noutras palabras, concibo o mapeamento dos datos espaciais extraídos da obra literaria coma unha ferramenta de análise que facilita vías alternativas de interpretación para tirar conclusións inéditas sobre a produción, transformación e función dos espazos literarios. Polo tanto, o obxectivo último de analizar o texto á luz da cartografía literaria é proporcionar un novo enfoque para o estudo dos seus espazos ficcionais.

Aínda que de forma moi variábel, a literatura achega información sobre os elementos espaciais que a compoñen, as súas características e as súa función. A aplicación á literatura dunha análise desde os presupostos da cartografía literaria esixe a vinculación dos espazos ficcionais a unha sección xeográfica da realidade para que poidan ser localizados nun mapa. Por esta razón, a cartografía literaria baséase na concepción de que a ficción se refire ao mundo real. A relación entre cartografías e espazo ficcional fundaméntase no concepto de localización, que designa o "act of translation" (Bulson, 2010, p. 24) polo cal os diferentes espazos do texto literario son representados nun mapa a través de símbolos. Con respecto a este proceso, cómpre matizar que na ficción literaria aparecen diferentes tipos de localizacións, moitas veces transformadas en diverso grao, debido ao emprego, por parte do autor, de distintos procedementos retóricos. Estes poden abranguer desde o uso de topónimos identificábeis ou o desenvolvemento de amplas descricións de espazos existentes, até a configuración de lugares á marxe da realidade empírica (Piatti e Hurni, 2011, p. 219). Polo tanto, as representacións cartográficas do espazo literario deben permitir extraer novas conclusións respecto ao texto, a pesar de que poida resultar imposíbel mapear a complexa totalidade dos elementos que serven á construción do lugar no relato ficcional, tal como apuntan Piatti, Bär, Reuschel, Hurni e Cartwright (2009, p. 184). Non obstante, o texto ficcional debe remitir, de forma máis ou menos directa, a un referente espacial real e específico, é dicir, a unha localización determinada nun momento histórico máis ou menos concreto, a pesar do cambio ao que poida dar lugar a súa recreación ficcional. Isto débese a que a cartografía literaria implica a sistematización da conexión entre espazo empírico e espazo textual. A especificidade da súa dimensión científica 
reside en que, mediante unha metódica representación das correspondencias entre o espazo real e o ficcional, sería posíbel detectar cal é a información mapeada e a non visualizada para desentrañar a súa significación, alén da simbolización da realidade a partir dun discurso (Schlögel, 2003, p. 23). Ante esta tesitura, a análise que vou presentar supón, na súa totalidade, unha aproximación que vai empregar a cartografía dixital como un método heurístico para captar e interpretar a dimensión espacial do texto literario, partindo do principio de que os espazos ficcionais de $A$ porta de palla poden aludir á xeografía empírica. Esta premisa baséase en que innumerábeis propiedades, manifestacións de actividades e procesos son susceptíbeis de representación cartográfica.

No ámbito das creacións literarias, o xénero narrativo en xeral e a novela en particular implican a recreación duns feitos, de modo que o vínculo entre literatura e espazo resulta ineludíbel. En consecuencia, non parece concibíbel a consecución dunha historia ficcional que non artelle ou se refira explícita ou implicitamente a un espazo, constituíndose esta categoría como condición literaria. De feito, o argumento dunha obra literaria implica a creación e o despregar dos lugares onde se desenvolven as accións, mais non é imprescindíbel que o espazo literario remita á realidade física, lexitimada xeográfica e topograficamente. Non obstante, advirte Piatti (2008, p. 15), os escritores tenden a situar a acción das súas obras en lugares cos que estabelecen un nexo de unión ou atracción até o punto de que, en moitas ocasións, os lectores poden trazar unha relación permanente entre autores e espazos específicos. En calquera caso, a dimensión espacial é a única que permite transparentar esta permeabilidade ou contacto entre mundo literario e extratextual (Piatti, 2008, p. 9). En contraste, os compoñentes ficcionais que constitúen personaxes e acontecementos, aínda podendo presentar ou remitir a referentes reais, estes tenden a ser (re)coñecidos polo autor en exclusiva -agás en casos moi puntuais, por exemplo, cando se trata de certos personaxes e feitos históricos. En cambio, o espazo onde se recrea unha obra literaria forma parte, moitas veces, da experiencia compartida de ambos os dous, autor e lector, xa que se constrúe a partir dos atributos empíricos da imaxinación, pero tamén da realidade que o lector pode apreciar en función da súa experiencia vital extrínseca. É dicir, estas propiedades espaciais representan un ámbito parcial da realidade na que se desenvolve o lector (Hillebrand, 1971, p. 35). Agora ben, a pesar deste status intermedio, poden xurdir dificultades ou limitacións de identificación do espazo por parte do lector a raíz da falta de coñecemento compartido co autor. En función destas observacións, resulta conveniente reflexionar sobre as particularidades do mapeamento dos espazos ficcionais recreados por Risco en $A$ porta de palla.

\section{A ESPECIFICIDADE DA REPRESENTACIÓN CARTOGRÁFICA DE A PORTA DE PALLA}

De acordo co obxectivo de analizar as características específicas do escenario contrafactual de $A$ porta de palla a partir da súa representación cartográfica, resulta conveniente comezar extraendo a información espacial que inclúe. No presente estudo, os datos espaciais do texto son subtraídos a partir da súa análise previa, tendo en conta que Risco traza mediante o argumento da novela un mapa narrativo dos espazos ficcionais. Por tanto, as cartografías destinadas a visualizar os lugares da narración supoñen unha representación semiótica en segundo grao sobre o desenvolvemento autorial do espazo da novela. Esta información aparecerá recollida nunha base de datos, clasificada en función de diversas tipoloxías segundo as súas características específicas ${ }^{6}$. 
Unha vez recompilados os datos espaciais que proporciona a obra literaria, a análise dos seus vínculos posíbeis e particulares con respecto aos emprazamentos empíricos debe ir precedida do seu deslinde e inventario en unidades de lugar, de acordo coas súas posíbeis relacións coa xeografía empírica. Este estudo faise partindo dunha valoración holística, que considera a natureza contrafactual do espazo, segundo o exposto. En correspondencia con este propósito, vou presentar unha tipoloxía de elementos espaciais que vai servir para estabelecer unha categorización inicial dos lugares rexistrados na novela ${ }^{7}$.

En primeira instancia, distingo dous tipos de entidades espaciais básicas na literatura, segundo as súas dimensións e relación: settings ou puntos e zonas. A primeira categoría designa as localizacións que se corresponden no texto cunhas coordenadas xeográficas específicas de latitude e lonxitude -X e Y-, á marxe da actuación dos personaxes. Os puntos representan a unidade espacial mínima mapeábel e indivisíbel -é dicir, non albergan outros puntos- e institúense como elemento primixenio a partir do cal se definen as demais entidades desta tipoloxía. Por outra parte, son zonas as referencias de lugar que, conforme aparecen concibidas nos textos ficcionais, son susceptíbeis de albergar no seu interior puntos. Neste sentido, a diferenza entre puntos e zonas é funcional e depende da escala variábel do espazo na ficción. Polo tanto, ao longo dunha obra literaria, unha mesma referencia espacial pode operar como punto ou como zona se alude a unha área xeográfica conceptualizada, respectivamente, de forma unitaria ou, pola contra, é susceptíbel de se segmentar ao dar cabida a puntos ${ }^{8}$.

Por unha banda, esta tipoloxía inicial de puntos e zonas favorece a diferenciación de todas as unidades espaciais que integran A porta de palla. Inclúe, por exemplo, puntos recorrentes na obra coma o palacio do bispo Baldonio, a catedral, as portas da cidade ou a soñada e posteriormente atopada porta de palla, pero tamén outros lugares como Strandia ou San Flemo. Do mesmo xeito permite distinguir zonas como a cidade de Nerbia ou a de Roma.

A partir da conceptualización espacial que proporciona esta tipoloxía inicial de puntos e zonas, o estudo cartográfico da novela debe incluír a adxudicación de novas variábeis a cada referencia de lugar co obxectivo de posibilitar o seu mapeamento.

A representación cartográfica de calquera texto implica lidar cunha serie de dificultades que atinxen á xeolocalización, é dicir, ao proceso de trasladar ás coordenadas dun mapa a información espacial extraída e clasificada. A orixe desta problemática ten que ver coa especificidade semiótica dos espazos textuais, dado que resulta posíbel recorrer a un amplo espectro de técnicas discursivas para concibir e confeccionar un escenario, podendo subliñar ou esborranchar as conexións cun espazo xeográfico existente (Piatti, 2017, p. 50). En correspondencia, as localizacións dos textos literarios non sempre representan unha reprodución realista ou exacta do espazo empírico, aínda que se relacionan con frecuencia cunha contrapartida nel (Piatti, Bär, Reuschel, Hurni e Cartwright, 2009, p. 180). De feito, un espazo literario pódese xestar a partir dunha vinculación inespecífica coa xeografía real ou incluso pode prescindir de calquera tipo de conexión con ela, creando mundos novos a partir de lugares imaxinarios, tal como sinalan Piatti, Bär, Reuschel, Hurni e Cartwright (2009, pp. 180-84) ou Piatti e Hurni (2011, p. 220). Na narración estudada rexístranse ambas as dúas posibilidades. Por unha parte, Risco, a través de referencias difusas á realidade, vai recrear, entre outros casos, a cidade de Nerbia ou mesmo a porta de palla, unha referencia posíbel e vagamente localizábel. Por outra parte, cando Baldonio volve de visitar o santo Ascanio na súa ermida para lle preguntar sobre o paradoiro de Rosinda, atravesa un lugar que se describe "como o baleiro absoluto, como viaxar a través do nada impalpábel”, unha "chaira sen fin, na que non se 
levantaba po nin soaban as ferraduras, nin se sentía o paso do cabalo, nin o peso do corpo, nin a temperatura, nin o ar [...] un mundo árido, morto, noutro planeta" (Risco, 2020, pp. 89). Neste segundo caso, trátase dun exemplo de espazo irreal.

En calquera caso, nos textos literarios, a ficción engade un elemento de complexidade e as dificultades de xeolocalización súmanse ás que son comúns a outro tipo de discursos. Así, por exemplo, hai espazos ficcionais que non remiten de maneira directa a un determinado lugar existente, pois xéstanse a partir da confluencia de varios emprazamentos reais ou tamén ficticios. Deste modo, xorden localizacións como a cidade de Nerbia, xerada a partir da reforma dunha urbe empírica como é Santiago de Compostela. En consecuencia, os métodos de produción do espazo literario implican a miúdo certas dificultades á hora de vincular a súa conceptualización ficcional coas correspondentes localizacións reais.

De acordo con Piatti, Reuschel e Hurni (2009a), a filiación entre realidade xeográfica e espazos literarios pon de manifesto a operatividade de tres factores: as posibilidades de localización, a transformación e a fragmentariedade. A primeira variábel refírese á viabilidade de asignar coordenadas específicas a un lugar literario, xa que as cartografías, de acordo coa súa función de amosar os límites dos fenómenos representados, operan con límites estabelecidos de maneira precisa. Agora ben, aínda que algúns espazos ficcionais se correspondan cunha localización real específica, outros poden resultar difíciles de situar no espazo empírico. De maneira xeral, os textos ficcionais ofrecen información xeográfica ou topográfica parcial -por exemplo, a raíz da multiplicidade semántica na descrición dun mesmo lugar ou do emprego de termos xeográficos vagos (Piatti e Hurni, 2011, pp. 219-20). De feito, a retórica empregada na narración pode incluso operar "explicitly against a precise location" (Piatti e Hurni, 2011, p. 220). Por último, hai espazos literarios cun referente real que se pode revelar inmapeábel, cando, debido á falta de información xeográfica no relato, resulta imposíbel delimitar a súa situación. É o caso, na novela estudada, da ermida onde se refuxia o santo Ascanio, nunha montaña, fóra das murallas de Nerbia. Neste exemplo, o autor non ofrece ningún detalle sobre a residencia do personaxe que permita postular a localización do seu acubillo.

Con respecto ao factor da transformación espacial, desde unha perspectiva empírica e literaria, atinxe tanto as alteracións do espazo extratextual que repercuten na creación da ficción como as modificacións retóricas da xeografía real. Por unha banda, os cambios espaciais atinxen a aqueles lugares reconfigurados ou desaparecidos da realidade -normalmente espazos urbanos, dada a súa predisposición a sufrir modificacións constantes- que o escritor preserva na ficción coas súas características orixinarias, como é o caso da muralla e das portas de Nerbia. Por outra parte, as alteracións do espazo literario abranguen tamén lugares reais que o autor decide remodelar por exemplo a propia Nerbia- ou eliminar. Estas transformacións espaciais afectan igualmente aos topónimos que, no mundo empírico, poden sufrir modificacións ao desaparecer debido a acontecementos históricos significativos -tales como invasións ou actuacións políticas. Esta última situación concirne na novela, por exemplo, á praza do Paraíso, hoxe coñecida como praza da Inmaculada ou da Acibecharía. Non obstante, o lugar en cuestión recibiu na realidade este nome debido ao ciclo bíblico correspondente á Xénese que estaba representado na fachada románica da catedral santiaguesa. Do mesmo xeito, os nomes de lugar poden sufrir cambios lingüísticos, a raíz da converxencia ou evolución da(s) lingua(s) dun determinado espazo. Na ficción, o escritor pode recuperar e manter a versión orixinaria de topónimos desaparecidos ou alterados, modificar ou suprimir os contemporáneos, como fará Risco, ou incluso crear outros novos. En calquera caso, as transformacións espaciais van esixir unha investigación previa sobre a súa historia para pescudar se 
un determinado espazo existiu, sufriu alteracións ou é unha invención do autor (Reuschel e Hurni, 2011, p. 297).

Finalmente, a variábel da fragmentariedade refírese ao dinamismo do espazo ficcional que implican os movementos a través del ou, tamén, aos cambios de escenario á marxe de calquera desprazamento. Por conseguinte, a totalidade dos movementos dos personaxes -tanto a través dun espazo determinado como dun punto a outro- raramente aparece indicada no texto. Do mesmo xeito, o conxunto de elementos espaciais que implica un cambio de escenario non sempre se recolle de maneira detallada no discurso. Máis habitual resulta a inclusión de parte destes emprazamentos, así como dunha dirección xeral ou imprecisa no caso dos movementos (Piatti, Bär, Reuschel, Hurni e Cartwright, 2009, p. 190). Por conseguinte, a localización de certos lugares e traxectos ficcionais implica, na meirande parte dos casos, unha interpretación ulterior a partir da información espacial presentada no texto.

En definitiva, esta taxonomía de tres principios aglutina distintos procedementos de representación dos espazos literarios, atendendo ás analoxías e diverxencias que presentan con respecto á realidade. Ademais, esta clasificación pon de manifesto a preponderancia das posibilidades de localización sobre as variábeis de transformación e fragmentariedade. Polo xeral, a detección de alteracións xeográficas ou retóricas dun emprazamento literario pode postularse a partir da posición do seu presumíbel reflexo real. Do mesmo xeito, a alternancia de espazos literarios estabelécese con base no coñecemento previo da presunta localización do seu referente empírico. De maneira específica, no estudo do espazo contrafactual xestado en $A$ porta de palla, acada unha importancia capital a complexa vinculación de Nerbia co referente empírico de Santiago de Compostela. Este nexo vai subxacer á representación novelística -máis ou menos alterada-, non só dos monumentos artísticos e históricos representativos da urbe empírica, senón tamén da súa contorna.

\section{LOCALIZACIÓN E RELEVANCIA ESPACIAL: UNHA TIPOLOXÍA DE ESPAZOS NON MAPEÁBEIS PARA A PORTA DE PALLA}

A cartografía literaria constitúe un método de análise que permite relacionar o espazo ficcional coa xeografía empírica a través do posicionamento. En virtude deste proceso, "la ficción es proyectada sobre el espacio geográfico [...] para dotarlo de una dimensión imaginaria” Cabo (2020, p. 158). Agora ben, aínda que a disciplina se basea no nexo coa xeografía empírica que transparenta o lugar nos textos ficcionais, as representacións cartográficas elaboradas baixo os seus presupostos débense concibir como "interfaz", é dicir, como "una conexión funcional entre dominios de naturaleza distinta -material o simbólica- que hace del borde o límite entre estos ámbitos un mecanismo transductor y, por tanto, decisivo en sí mismo" (Cabo, 2020, pp. 166-67). Polo tanto, os mapas literarios non se sustentan nunha oposición binaria entre espazo real e literario. Isto débese a que as representacións dos emprazamentos literarios supoñen construcións sociais e históricas elaboradas a partir dos lugares reais, en consecuencia, a ficción dá cabida ao espazo destes referentes. Deste xeito, as cartografías ficcionais serven para analizar a correspondencia entre as características topográficas dos espazos literarios e estes últimos. Á hora de determinar este nexo, a localización xoga un papel fundamental, pois os mapas fundaméntanse en técnicas de representación encamiñadas a amosar unha posición concreta na superficie terrestre de acordo coa súa lonxitude, latitude e altitude (Ungern-Sternberg, 2009, p. 233). Polo tanto, a localización implica 
adscribir, de maneira xustificada, unidades ficcionais de lugar con coordenadas xeográficas reais. Ademais, supón un factor determinante no estudo dos datos espaciais pois, como advirte Kemp (2010, p. 48), os resultados variarán se varía a localización dos obxectos de análise.

A representación cartográfica dos lugares ficcionais rexistrados en A porta de palla baséase no suposto, heurístico e provisional, de que poden ser localizábeis. Non obstante, un estudo individualizado das diferentes unidades espaciais revela que só algunhas remiten, ben de forma directa, ben mediante descricións ou outra información de carácter indirecto, a lugares empíricos. O espazo ficcional do texto literario está composto por unidades configuradas de maneira específica que resultan recoñecíbeis e catalogábeis, mais tamén entran en xogo na xestación dos lugares ficcionais características importantes, propias da escrita e da literatura, que non se poden medir nin, polo tanto, localizar (Ungern-Sternberg, 2009, p. 235). Á hora de estabelecer a correspondencia entre os datos espaciais da obra literaria e o seu equivalente real, a falta de exactitude que habitualmente caracteriza os primeiros ${ }^{9}$ esixe un estudo especializado. De feito, en casos tan complicados como o da xestación dun espazo contrafactual, só se poden apuntar as localizacións despois dun estudo coidadoso da lectura e das súas hipotéticas contrapartidas no mundo empírico (Piatti e Hurni, 2011, p. 220). A continuación, cómpre resolver tanto se a información espacial do relato favorece a vinculación con coordenadas xeográficas reais como se a súa representación cartográfica resulta transcendente. Para cumprir con este último obxectivo, convén conceptualizar a información espacial de interese, segundo os obxectivos do estudo textual estabelecidos de antemán, pois son os que van determinar a posibilidade ou a utilidade de cartografar certos emprazamentos. No caso de $A$ porta de palla, o mapeamento dos compoñentes espaciais que sustentan a ficción debe permitir examinar o proceso de construción do mundo contrafactual e as súas implicacións.

De acordo con este propósito, a partir das características narrativas de cada lugar, no marco deste estudo, estabelezo a seguinte tipoloxía encamiñada a dirimir a inviabilidade da súa cartografía: os espazos xenéricos e os funcionais ${ }^{10}$. Esta proposta implica, nunha primeira fase, a exclusión dunha serie de espazos que desbordan as posibilidades de mapeamento. Esta circunstancia deriva da carencia ou exceso de datos que supoñen os procedementos retóricos empregados polo escritor para producir estes emprazamentos. En función de dous factores, a relevancia e a integridade dos datos xeográficos, a análise dos lugares que integran a novela pon de manifesto a recorrencia de certos lugares inviábeis ou imposíbeis de representar cartograficamente.

No caso dos espazos xenéricos, a información espacial do texto remite a un sector xeográfico do mundo empírico que, dada a súa amplitude e inespecificidade, queda desprovisto de carácter distintivo. Son exemplos deste tipo, entre moitos outros, os lugares que atravesa Baldonio en soños, de Nerbia a Roma, mentres está convalecente: "camiños e calzadas, pontes e ríos, chairas secas cheas de po [...] outeiros e montañas, bosques mestos [...] pantanos pegañentos [...] montañas altísimas [...] lagos xeados [...] mares, foxos, precipicios [...]" (Risco, 2020, p. 48). En todos estes casos, a representación cartográfica dos espazos designados non resulta posíbel dada a falta de datos sobre a localización de cada elemento particular. Así e todo, sería posíbel sinalar no mapa as diferentes rexións que se han de cruzar para ir de Santiago de Compostela a Roma, pois todas as referencias supoñerían partes diferenciadas delas. Non obstante, o mapeamento completo do territorio ao que se refiren daría lugar a representacións superfluas do espazo novelístico. No segundo caso, as referencias non son suficientes para estabelecer unha correspondencia entre espazo literario e realidade. Fronte aos xenéricos, os lugares funcionais son entidades discretas con características 
definitorias que se poden estabelecer á marxe da súa localización. Esta última, na fin de contas, resultaría en certa medida modificábel ou superflua. Na novela estudada representan exemplos destacábeis de espazos funcionais, entre outros, a ermida na que se refuxia o santo Ascanio ou a casa de Galafre, situadas ambas as dúas extramuros mais na contorna de Nerbia.

En definitiva, o mapeamento dos lugares ficcionais que encaixan en calquera destes grupos resulta intranscendente ou inviábel debido a un exceso de información, á falta de datos espaciais ou á súa conceptualización á marxe da realidade. Non obstante, trátase de espazos que contribúen a completar o mapa narrativo que desenvolve Risco na novela. Neste senso, a pesar dos numerosos elementos espaciais cunha representación cartográfica impracticábel ou irrelevante, a novela estudada axústase á principal premisa que define os emprazamentos contrafactuais: a correspondencia entre os lugares narrativos e unhas coordenadas xeográficas máis ou menos determinadas.

\section{LOCALIZACIÓN E TRANSFORMACIÓN ESPACIAL: UNHA TIPOLOXÍA DE ESPAZOS MAPEÁBEIS PARA A PORTA DE PALLA}

Ante esta tesitura, o estudo cartográfico de $A$ porta de palla inclúe o desenvolvemento de diferentes categorías, que faciliten a xeolocalización dos espazos mapeábeis rexistrados, tendo en conta as variábeis da transformación e da fragmentariedade. Neste senso, a transformación atinxe, de maneira xeral, a diferenciación estabelecida na novela entre os espazos literarios e os seus reflexos reais, como é o caso de Nerbia e Santiago de Compostela. Deste xeito, nas correspondencias espaciais entre os lugares empíricos e ficcionais que establecerei nas seguintes liñas susténtase a concepción da novela como historia contrafactual.

Unha taxonomía que explore as singularidades de cada elemento espacial mapeábel debe atender, en primeiro lugar, ao grao de referencialidade. Este parámetro foi definido por Piatti (2017, p. 46) como o nivel de detalle co que un texto literario evoca a xeografía empírica: desde o mimetismo e as alusións até a superposición, reestrutura ou cambio de lugares, tanto derivados da realidade como ficticios. En función da referencialidade, os espazos rexistrados en $A$ porta de palla poden clasificarse en tres categorías. De acordo co maior ou menor realismo topográfico e toponímico da súa configuración particular, os puntos e zonas da novela poden ser importados, inventados ou transformados ${ }^{11}$.

As referencias espaciais máis próximas ao mundo empírico son os lugares importados, isto é, espazos ficcionais que evocan un equivalente real. Noutras palabras, trátase de incorporar á ficción localizacións empíricas. Agora ben, á hora de aplicar esta categoría aos espazos da novela hai que ter en conta dous factores que serán explorados máis adiante. Dunha parte, as referencias de lugar detectadas na novela aparecen vinculadas a diferentes tempos históricos. Doutra parte, as cartografías derivadas do texto constitúen mapas elaborados a partir da xeografía actual. Polo tanto, nesta categoría de espazos inclúense aquelas referencias toponímicas ou topográficas correspondentes a lugares existentes ou desaparecidos que non sufriron alteracións retóricas no tocante ás súas características ficcionais. Trátase de puntos como "Toledo", "Fez" ou mesmo o "Palacio Pontificio" romano (Risco, 2020, p. 82, 192) e tamén de zonas como "Roma" ou as terras dos "medos", "persas" e "filisteos" (Risco, 2020, p. 129). A análise cartográfica vai poñer de manifesto que Risco sustenta minimamente o escenario contrafactual da novela sobre a xeografía empírica. 
Este feito pode resultar rechamante e pasar desapercibido á marxe dun exame espacial a través dos mapas, pois o levantamento do escenario alternativo implica, maioritariamente, a modificación da realidade xeográfica na que presumibelmente se sustenta.

Tras os espazos importados sitúanse os inventados, que existen só na ficción pero evocan coordenadas xeográficas reais. Polo tanto, a posición dos lugares inventados indícase na propia ficción, pois non remiten a un reflexo real específico. Noutras palabras, estes emprazamentos só posúen entidade textual e representan unha categoría espacial máis distanciada da realidade que os anteriores. En A porta de palla, esta clase de lugares inclúe un único punto mapeábel. Trátase da alusión recorrente á porta de palla, concibida como porta principal de entrada a Roma, talvez a xeito da desaparecida Porta Flaminia, Porta do Popolo ou Porta San Valentino que se abría á praza homónima. En calquera caso, este espazo inventado, de acordo cos datos espaciais da narración, sitúase en Roma ${ }^{12}$ e supón un emprazamento individual que o autor ficticio agrega desafiando o espazo empírico e rexistrado historicamente de maneira oficial. Este procedemento representa "a classic literary-geographic move: adding a nonexistent element to an existing territory to create a suitable setting for a fictional scene" (Piatti, 2017, p. 48).

Por último, na recreación ficcional do espazo que Risco leva a cabo en A porta de palla é posíbel detectar un amplo grupo de lugares transformados. Integran esta categoría aqueles espazos cunha topografía ou toponimia que responde a alteracións, deliberadas e responsabilidade do escritor, da xeografía empírica á que hipoteticamente aluden. Fronte ás categorías anteriores, representan un menor grao de referencialidade, pois, se se someten a un enfoque cartográfico, son datos espaciais que requiren a interpretación do especialista á hora de determinar os seus presuntos nexos coa xeografía empírica. Pola contra, a posición dos tipos de lugares xa analizados infírese da información textual, sen necesidade de que esta sexa elucidada. En consecuencia, o uso desta clase de espazos implica unha difuminación referencial. Os lugares transformados da novela en moitos casos constitúen topónimos referidos a lugares sobre os que recaen ou exercen a súa xurisdición diferentes títulos ou dignidades. Debido ás relacións políticas que estabelecen co conde bispo Baldonio de Nerbia, os máis recorrentes son "o duque de Strandia, o margrave de Inlandia, os condes de Aldrat e de Conagón" xunto co "gran mestre da orde militar de San Flemo" (Risco, 2020, p. 107) ou a "Condesa de Dagán" (Risco, 2020, p. 182). Estes exemplos parecen remitir respectivamente ao ducado de Normandía, á marca de Austria $^{13}$, ás terras relacionadas coas familias Andrade e Mondragón e tamén ao condado de Lemos e ao de Bazán. Ademais, o topónimo "Dauberga” ao facer referencia a un "cabaleiro [...] que mandaba a escolta", procedente de Strandia, "que custodiaba a Baldonio" (Risco, 2020, p. 192 ) podería aludir á cidade normanda de Cherburgo. De maneira semellante, outra restra de espazos narrativos serve para identificar os inimigos relixiosos de Baldonio, dados os seus vínculos con Roma e co santo pai. Trátase de lugares como "San Papucio", "Palmirania", "Ascalino", "Santa Polonia", "Malinópolis", o "mosteiro de San Pacomio", a "basílica Lateranense" ou "Alonia" (Risco, 2020, pp. 192-193). Estes topónimos poderían corresponderse, por orde, cos municipios ou vilas italianos de San Paolo, Palmira -actualmente Oppido LucanoScala e Santa Apollonia, coa cidade de Milán, coa abadía de San Pablo -a única abadía de Roma-, coa basílica de San Xoán de Letrán e coa cidade de Bolonia. Polo tanto, en A porta de palla os procesos de transformación nominal e física dos espazos ficcionais basearíanse en tres factores primordiais: os feitos -históricos e ficcionais-, a similitude fonolóxica, as relacións semánticas, a topografía ou a sátira ${ }^{14}$. De acordo con estes parámetros, o exemplo máis representativo de transformación espacial é o da cidade de Nerbia e os seus emprazamentos constituíntes. Xunto 
coa topografía, como xa se viu, os feitos históricos e narrativos permiten identificar Nerbia con Santiago de Compostela, que adquiriu en 1120 o rango de arquidiocese -o seu equivalente narrativo sería o de condado e bispado- estabelecéndose como continuadora da diocese de Iria Flavia. Certa similitude fonolóxica entre este último topónimo e o de Nerbia queda patente ${ }^{15}$. Toda esta análise convida a reflexionar sobre a importancia das transformacións espaciais na novela. Risco sustenta as alteracións do espazo empírico, sobre todo, nos nomes de lugar e esta elección non é casual. Tal como apunta Besse (2017, p. 22), os topónimos estimulan a inventiva ao mesmo tempo que favorecen o tránsito dun emprazamento a outro ou á totalidade dunha urbe. Ao mesmo tempo, converten o espazo dunha cidade no espello doutros lugares. En concreto, en A porta de palla, a través da modificación toponímica, Risco suscita as reflexións do lector e pon de manifesto o seu obxectivo de converter a urbe ficcional no reflexo do seu presumíbel referente empírico. En todos os casos, as transformacións espaciais desenvolvidas na novela, independentemente das súas características, débense á intervención do escritor, que altera de maneira consciente e intencionada a realidade. Deste xeito, seguindo os postulados de Besse (2017, p. 31) sobre a toponimia ficcional, a narración aparece ancorada nunha serie de emprazamentos que, en xeral, o lector pode recoñecer ${ }^{16}$. 0 escritor configura a súa ficción non só a partir de descricións espaciais, senón tamén a través de renomeamentos e remodelacións, cun poder de evocación intrínseco que converte a cidade literaria nunha refracción do seu suposto referente real. Polo tanto, os espazos transformados desta novela operan sobre o papel dos topónimos na interacción entre cartografía e literatura, unha transición adxacente do suposto reflexo empírico á ficción. En virtude deste procedemento, Risco consegue amosar como os feitos narrados poden remitir a lugares localizábeis que, seguindo as indicacións de Besse (2017), posúen "unsuspected, unexpected, imperceptible narrative powers in current evocations of the same setting" (p. 31). Ao mesmo tempo, esta transformación toponímica e topográfica dos espazos narrativos é, primordialmente, a que converte a novela nun mapa depósito da ficción, pois os espazos transformados son o resultado da remodelación creativa e subxectiva do espazo ficcional que leva a cabo Risco, de aí a necesidade de interpretar os datos textuais para os vincular cos seus potenciais reflexos. En calquera caso, a través das transformacións do espazo, Risco pon de manifesto o estatuto ficcional da narración e consolida a súa verosimilitude.

\section{A REPRESENTACIÓN CARTOGRÁFICA DE A PORTA DE PALLA}

Fronte á carencia de similitude entre as palabras e o espazo ficcional que simbolizan, as cartografías literarias poden ofrecer unha representación máis inmediata deste último, pois van incluír puntos, liñas e polígonos de cores que van servir para sinalizar as características ou os v́inculos dos espazos ficcionais, xa sexa con respecto á realidade xeográfica, xa sexa entre si. Son os Sistemas de Información Xeográfica os que posibilitan o desenvolvemento de representacións cartográficas de diferente tipo. Neste caso concreto, os mapas coa información íntegra, correspondente a cada categoría espacial, reproduciranse de maneira conxunta, no seguinte formato Esri Story Map correspondente, en concreto, a un Map Series. Este último permite, a partir de paneis laterais, o acceso ás cartografías así como ao resto da información de diferente tipo que as acompaña no seguinte enlace: https://arcg.is/P19K9.

A seguir, xa que logo, realizarei a análise sobre as particularidades do espazo contrafactual xestado na novela en función das representacións cartográficas resultantes. No tocante aos espazos importados os presuntos referentes destes puntos ocupan os territorios de tres continentes: Asia, 
África e Europa. Máis polo miúdo, fronte ás alusións a lugares europeos destacan aquelas que encadran na concepción ilustrada e romántica de Oriente. Na mesma liña, os presumíbeis reflexos das zonas importadas atinxen maioritariamente a territorios asiáticos, pois só se rexistra unha única referencia europea -en concreto, á cidade de Roma. Esta análise cartográfica serve para poñer de manifesto que Risco recorre escasamente á xeografía empírica para construír un marco de referencia espacial en torno ao mar Mediterráneo. Este feito resulta destacábel, posto que os espazos importados non son recorrentes na narración. Por esta razón, pode pasar desapercibido á marxe dun exame espacial a través dos mapas, xa que a construción do espazo alternativo a partir da cidade de Nerbia vai supoñer, na meirande parte dos casos, a modificación da realidade xeográfica na que potencialmente se sustenta.

En segundo lugar, o estudo do mapa correspondente ao único lugar inventado que se rexistra en $A$ porta de palla permite constatar que, a pesar de ser un punto recorrente ao longo de toda a obra e até valer de título, é o único exemplo integrante desta categoría espacial. Non obstante, a súa relevancia parece derivar precisamente da súa exclusividade. Se cadra, o uso restrinxido desta clase de lugares débese tamén a que non evocan un reflexo real e, polo tanto, non favorecen o recoñecemento dun posíbel vínculo entre espazo xeográfico e ficcional, alén de contribuír á alteración dos constituíntes deste último para reforzar o distanciamento con respecto ao primeiro.

A continuación, os espazos transformados representan a categoría de lugares máis numerosa das rexistradas na novela. Estes datos xeográficos evidencian que o espazo ficcional se configura maioritariamente a partir da transformación topográfica ou toponímica de certos segmentos da xeografía empírica e non só a través da súa simple reprodución. Os presuntos referentes dos puntos transformados aglutínanse na cidade literaria e despréganse por diversos territorios galegos, italianos, franceses e, en menor medida, austríacos. A análise cartográfica permite constatar que as alusións aos constituíntes da cidade prevalecen sobre as remisións aos demais reflexos. En correspondencia, o potencial referente da única zona transformada da obra atinxe á parte monumental de Santiago de Compostela. Ademais, os hipotéticos reflexos tanto dos puntos como das zonas transformados repítense na práctica totalidade dos capítulos da novela. Polo tanto, as transformacións espaciais da novela atinxen, primordialmente, a aqueles emprazamentos onde se desenvolven os feitos. A partir destes lugares fórxase a natureza contrafactual do escenario novelístico. 0 conxunto dos espazos transformados permite apreciar unha relación fundamentada xeograficamente entre as referencias a espazos galegos e as rexións europeas do nordeste, pois a súa aparición ao longo da obra vincúlase a diversas formas de poder político -condes, duques, mestres ou margraves-, máis ca relixioso -mesmo Baldonio é conde. Pola contra, as alusións a lugares italianos e a outros lugares mediterráneos preséntanse na obra vinculadas a diferentes cargos relixiosos repartidos entre o santo pai e os seus subordinados. Parece tamén relevante sinalar que as primeiras referencias son máis numerosas e recorrentes que as segundas. Deste xeito, malia que Risco somete ambos os dous tipos de referencias a un mesmo proceso de difuminación referencial -histórica, temporal, política e cultural- esta última atinxe, en menor medida, aos espazos italianos.

A lectura dos mapas revela, en todos os casos, detalles que quizais pasen inadvertidos se non se afonda no exame do espazo alternativo a través da súa representación cartográfica. En concreto, pon de manifesto como o autor na obra desenvolve unha anexión -de carácter político e relixiosoentre a civilización atlántica ou da memoria e a mediterránea ou da intelixencia, deconstruídas referencial, cronolóxica, histórica, política e culturalmente (Risco, 1920, pp. 32-33). Non obstante, ao mesmo tempo, evidencia a puxa entre a civilización atlántica e as outras dúas -mediterránea e oriental-, tendo en conta as referencias espaciais empíricas que atinxen a estas últimas. Deste 
xeito, o estudo levado a cabo sobre o espazo en $A$ porta de palla permite extraer unha serie de conclusións con respecto ao seu horizonte contrafactual. Estas singularidades teñen que ver co modo de construción deste tipo de lugar, a diversidade de emprazamentos, o papel da cartografía no seu estudo, as conexións coa temporalidade e o propósito ideolóxico que subxace á súa creación.

\section{CONCLUSIÓNS: O HORIZONTE CONTRAFACTUAL}

Desde o inicio da novela, Risco, a partir da correspondencia coa realidade empírica, xera unha imaxe xeográfica selectiva e remodelada do mundo extraliterario. Deste xeito, os lectores asisten a unha reconfiguración ou remapeo de espazos coñecidos desde unha escala local a outra continental. En ambas as dúas, as localizacións creadas por Risco na novela representan o resultado de visións espaciais xurdidas do seu coñecemento da Historia a, da súa ideoloxía política e da tradición relixiosa. Esa información é material suficiente para que o escritor outorgue á súa novela un estatuto contrafactual, en virtude do cambio deliberado dos seus potenciais referentes xeográficos empíricos. A deturpación ficcional dos espazos reais ten lugar de maneira implícita, pois antecede os feitos e revélase a través do seu desenvolvemento. Neste proceso de desenvolvemento espacial interveñen tanto os lugares inmapeábeis como os mapeábeis. 0 escritor usa ambos os dous tipos para elaborar a súa historia ficticia, orixinal e intransferíbel. Amais, este catálogo espacial pon de manifesto o vínculo indisociábel entre a creatividade dos tipos de espazos ficcionais propostos, a súa denominación e os seus significados. Máis polo miúdo, a análise cartográfica que veño de presentar serve para poñer de manifesto que Risco en case todos os casos emprega referencias toponímicas ou xentilicios á hora de designar os diferentes espazos narrativos mapeábeis. Non obstante, o escritor alicerza o escenario contrafactual da novela apenas sobre a xeografía empírica pois, malia que as zonas importadas van imperar sobre unha única zona transformada, os puntos transformados van ser moito máis numerosos que os importados. Ademais son os puntos e zonas transformados os que amosan unha maior recorrencia na narración.

Dunha banda, os espazos importados aparecen fóra das fronteiras da cidade literaria, contribuíndo a perfilar o mundo ficcional en que se insire e tamén serven para o vincular coa realidade histórica. Por este motivo, representan o fundamento da dimensión contrafactual do espazo, xa que evocan un pasado recoñecíbel e non inventado. Doutra banda, os lugares transformados atinxen os emprazamentos nos que se desenvolve a acción e serven para forxar a natureza alternativa do escenario novelístico. En concreto, evidencian a modificación deliberada da xeografía empírica que leva a cabo Risco na novela. Xunto a estes dous tipos de espazos, desde o inicio até o remate da narración alúdese a un único lugar inventado que dá título á obra. Trátase da porta atoada de palla que serve a Risco para esluír o vínculo entre o espazo ficcional e a xeografía empírica. Dada a súa natureza, este lugar inventado amosa o xeito en que o autor utiliza a ficción para cambiar a realidade.

A raíz destas particularidades, segundo a hipótese proposta, a novela pódese entender fundamentalmente a partir do desenvolvemento dun espazo contrafactual que implica a emerxencia dunha corrente temporal alternativa, en virtude da ontoloxía irreal do espazo onde opera (Piatti e Hurni, 2009, p. 333). Deste xeito, Nerbia preséntase como un lugar dunha época ontoloxicamente irreal, sustentado nunha cronoloxía medieval alternativa que abrangue, atendendo ás referencias espaciais, principalmente o século XII -coa Praza do Paraíso, a muralla, as portas da cidade ou as potenciais alusións ao condado de Andrade. Non obstante, poderíase 
estender até o século XV -época da fundación da Universidade. Ademais, a este marco cronolóxico vanse engadir elementos espaciais que supoñen anacronismos, dada a súa natureza temporal posterior á Idade Media -por exemplo, as presumíbeis referencias ao condado de Bazán. A teor desta análise, é mester apuntar que as novelas contrafactuais, como sería o caso, non impugnan os acontecementos históricos nin a súa cronoloxía, pois ambos os dous forman parte do xogo estético (Widmann, 2011, p. 188).

En calquera caso, a xestación de feitos e do espazo alternativos trae consigo o desenvolvemento de novas premisas en torno á Historia. Aínda sendo obviamente falsas, as narrativas contrafactuais implican o desenvolvemento dunha función cognitiva, nun marco epistemolóxico específico da historia intelectual e do coñecemento histórico compartido, que se debe fixar en cada caso concreto (Albrecht e Danneberg, 2011, p. 16, 19). Noutras palabras, resulta pertinente considerar a intencionalidade ideolóxica que subxace á xestación do mundo contrafactual, pois este tipo de narrativas serven ao propósito de cuestionar interpretacións dos feitos históricos asentadas na sociedade moderna, tal como apuntou Widman (2011, p. 189). Con respecto a esta finalidade, destacan na obra o papel do non cristián e a ausencia dunha dimensión nacional do espazo que deriva del. No tocante a estas cuestións, puidera ser que o uso do espazo nesta obra de Risco, entre outras, responda á intencionalidade de atenuar a relación entre a escritura e a Historia concibida como memoria e, xa que logo, en estreita conexión co atlantismo, froito dunha postura de descrédito do autor con respecto a este último. A recreación imaxinaria do espazo que leva a cabo Risco nesta novela desafía a réplica do mundo empírico. De maneira máis específica, o espazo contrafactual supón o xurdimento dunha realidade alternativa que se ofrece no sitio do que realmente aconteceu, propoñendo unha visión do mundo como debería ser e non como verdadeiramente foi. Esta perspectiva coincide co desenvolvemento no panorama literario español dunha teoría literaria que implicou o distanciamento da creación ficcional da realidade e da política. Así e todo, a pesar das alteracións posíbeis, o espazo recreado por Risco en A porta de palla presenta vínculos coa xeografía empírica. De feito, Galiza e, en particular, Santiago de Compostela, co seu palacio episcopal, van operar como localizacións substrato dun mundo ficcional que semella localizábel. Nel, Nerbia opera a modo de imaxe indiferenciada, sen lugares que favorezan a orientación, mais, á súa vez, evoca e pende dun reflexo extratextual que está presente tanto na inventiva do narrador como fóra dela. Trátase dun imaxinario espacial modificado segundo os propósitos de Risco que, en última instancia, evoca referentes extraídos da realidade. Esta unión coa realidade implica, na fin de contas, unha postura de desprendemento parcial con respecto ao papel da civilización atlántica e, de maneira específica, da nación galega, en relación ao esmorecemento de Europa para contribuír ao rexurdimento dunha nova civilización (Risco, 1920, pp. 32-33).

A porta de palla presenta a historia de redención de Baldonio de Strandia, conde e bispo disoluto da cidade de Nerbia. A través da figura do protagonista, Risco achega unha desmitificación e unha crítica non só da hipocrisía do poder eclesiástico senón tamén do político. A exposición pública da libertinaxe de Baldonio deixa ao descuberto o falseamento da Historia a prol dos intereses das clases dominantes. Por unha parte, a partir do momento en que o bispo recoñece os seus pecados e abandona a cidade, desencadéanse unha serie de revoltas campesiñas e señoriais que derivan no seu desgoberno. Por outra parte, cando o bispo abandona as fantasías ao servizo do poder político e eclesiástico -sobre un papado feminino e un imperio masculino encarnados, respectivamente, por Rosinda e mais por el (Risco, 2020, p. 49)-, perde todos os seus poderes. Conforme a estas consideracións, é posíbel inferir que en A porta de palla o proceso de desmitificación ao que Risco somete o poder eclesiástico sustenta unha crítica encuberta á Historia como lexitimadora do poder. 
Neste senso, ponse de manifesto que a escrita da Historia corre a cargo dos vencedores, razón pola cal a súa veracidade se pode considerar relativa. Polo tanto, a obra constitúe un exercicio ficcionalizante que remite ao propósito de esquecer o pasado histórico. 0 cuestionamento dos conceptos de Historia e memoria é froito do contexto en que xorde $A$ porta de palla. Risco escribe esta novela durante a posguerra franquista, isto é, nunha época de mitificación galopante da Falanxe e do Caudillo á conta dos medios de información do momento e da literatura fascista e historiográfica. Este etapa encaixa nun panorama de posguerra a nivel mundial e tamén de guerra fría que supuxo o deterioro social, cultural, relixioso e político de Europa e certos réximes. Se cadra, Risco subverteu na súa ficción as ideas nacionalistas, patrióticas, a concepción glorificadora dos conflitos armados -basta lembrar os campesiños que saen tomar Nerbia armados con apeiros de cociña e de labranza (Risco, 2020, p. 129)- ou o sacrificio individual para a preservación dos intereses dun Estado -nin a revolta encabezada por Galafre, nin o arrepentimento xenuíno de Baldonio serven para lle devolver o seu antigo esplendor á cidade-, ou o partidismo do clero e da nobreza, partidaria de lle retirar a Baldonio o seu poder. Á luz de todos estes datos, A porta de palla pode representar, na fin de contas e en virtude da súa configuración contrafactual, a crise dos relatos históricos e da posibilidade de que a crise que sofre a civilización mediterránea en Europa poida ser restituída pola atlántica (Risco, 1920, pp. 32-33). De aí a ausencia dunha dimensión espacial nacional.

\section{Bibliografía}

Albrecht, A. e Danneberg, L. (2011). First Steps Toward an Explication of Counterfactual Imagination. En D. Birke, M. Butter e T. Köppe (Eds.), Counterfactual thinking - Counterfactual writing (pp. 12-19). De Gruyter.

Besse, J-M. (2017). Cartographic Fiction. En A. Engberg-Pedersen (Ed.), Literature and Cartography. Theories, Histories, Genres (pp. 21-43). The MIT Press.

Bulson, E. (2010). Novels, maps, modernity: the spatial imagination, 1850-2000. Routledge.

Cabo Aseguinolaza, F. (2020). Ficción y lugar: los topónimos desde la teoría de la literatura. En O. M Silvestre e R. Patrício (Eds.), Conferências do Cinquentenário da Teoría da Literatura de Vítor Manuel Aguiar e Silva (pp. 153-173). Universidade do Minho.

Compostela geoliteraria (2017). Santiago de Compostela, España. https://www.compostelageoliteraria.or g/

Danto, A. C. (1965). Analytical Philosophy of History. Cambridge University Press.

Hillebrand, B. (1971). Mensch und Raum im Roman. Studien zu Keller, Stifter, Fontane. Mit einem einführenden Essay zur europäischen Literatur. Winkler.

Kemp, K. K. (2010). Geographic Information Science and Spatial Analysis for the Humanities. En D. J. Bodenhamer, J. Corrigan e T. M. Harris (Eds), The Spatial Humanities: GIS and the Future of Humanities Scholarship (pp. 31-57). Indiana University Press.

Piatti, B. (2008). Die Geographie der Literatur: Schauplätze, Handlungsräume, Raumphantasien. Wallstein.

Piatti, B. (2017). Literary cartography: mapping as method. En A. Engberg-Pedersen (Ed.), Literature and Cartography. Theories, Histories, Genres (pp. 45-72). The MIT Press.

Piatti, B. e Hurni, L. (2009). Mapping the Ontologically Unreal - Counter- factual Spaces in Literature and Cartography. The Cartographic Journal, 46(4), 333-342. https://doi.org/10.1179/000870409X12554 $\underline{350947386}$ 
Piatti, B. e Hurni, L. (2011). Cartographies of fictional worlds. The Cartographic Journal, 48(4), 218-223. ht tps://doi.org/10.1179/174327711X13190991350051

Piatti, B., Bär, H. R., Reuschel, A. K., Hurni, L. e Cartwright, W. (2009). Ma- pping literature -towards a geography of fiction. En W. Cartwright, G. Gartner e A. Lehn (Eds.), Cartography and Art (pp. 177-192). Springer.

Piatti, B., Reuschel, A. K. e Hurni, L. (2009a). Literary Geography - or How Cartographers Open up a New Dimension for Literary Studies. En 24th International Cartographic Conference, Santiago de Chile, Chile.

Plini, P., Di Franco, S. e Salvatori, R. (2016). One place one name? Dealing with toponyms in WWI. GeoJournal, 83, 87-99. https://doi.org/10.1007/s10708-016-9760-9

Reuschel, A-K. e Hurni, L. (2011). Mapping Literature: Visualisation of Spatial Uncertainty in Fiction. The Cartographic Journal, 48(4), 293-308. https://doi.org/10.1179/1743277411Y.0000000023

Risco, Vicente (1920). Teoría do Nacionalismo galego. Fundación Vicente Risco.

Risco, Vicente (1953). La puerta de paja. Planeta.

Risco, Vicente (1981). Obra completa 2. La puerta de paja. Gamalandalfa. La verídica historia del niño de dos cabezas de Promonta. Akal.

Risco, Vicente (2020). A porta de palla. Dr. Alveiros, Fundación Vicente Risco.

Rozas Arceo, Alba (2019). Fragmentos de Apocalipsis como ficción espacial. La condición contrafactual de Villasanta de la Estrella. Un análisis desde la cartografía literaria [Tese de doutoramento]. Universidade de Santiago de Compostela. http://hdl.handle.net/10347/23195

Schögel, K. (2003). Im Raume lesen wir die Zeit: Über Zivilisationsgeschichte und Geopolitik. Carl Hanser Verlag.

Soldevila Durante, I. (1996). Historia e ficcíon en La puerta de paja. En C. Casares (Ed.), Vicente Risco: actas do Congreso celebrado en Ourense os días 18, 19, 20 e 21 de outubro de 1995 (pp. 301-320). Xunta de Galicia.

Staley, D. J. (2007). History and Future: Using Historical Thinking to Imagine the Future. Landham. Lexington Books.

Ungern-Sternberg, A. (2009). Dots, lines, areas and words: Mapping literature and narration (With some remarks on Kate Chopin's “The Awakening”). En W. Cartwright, G. Gartner e A. Lehn (Eds.), Cartography and Art (pp. 229-252). Springer.

Weigel, S. (2002). Zum "topographical turn". Kartographie, Topographie und Raumkonzepte in den Kulturwissenschaften. Kulturpoetik, 2(2), 151-165. https://www.jstor.org/stable/40621671

Widmann, A. M. (2011). Plot vs. Story: Towards a Typology of Counterfactual Historical Novels. En D. Birke, M. Butter e T. Köppe (Eds.), Counterfactual thinking - Counterfactual writing (pp. 170-189). De Gruyter.

Notas

$1 \quad$ Este estudo está baseado no limiar que desenvolvín para a tradución ao galego da obra, que integra o cuarto volume da Biblioteca Vicente Risco, ao abeiro do Selo Doutor Alveiros da Fundación Vicente Risco (Risco, 2020). Amais, ao longo da miña análise emprego esta tradución porque inclúe fragmentos do manuscrito orixinal do autor que foron censurados nas primeiras edicións da obra e recuperados posteriormente, tal como apunta Salgado (Risco, 1981, pp. 6-7).

2 Para saber máis arredor da xénese da obra e da súa repercusión crítica tras ser presentada ao premio, consúltese o prólogo de Casado correspondente á primeira edición (Risco, 1953, pp. 5-8).

3 Sobre posteriores edicións e recepción crítica, consúltese tamén o prólogo á novela de Salgado (Risco, 1981, pp. 4-5).

4 Refírome en todo momento ao tempo histórico, pois os acontecementos narrados preséntanse fundamentalmente conforme ao seu transcurso lineal. 
5 A idea de que os libros narrativos e os historiográficos obedecen as mesmas pautas de confección foi defendida, entre outros, por Danto na súa obra Analytical Philosophy of History (1965).

6 Dispoñíbel en formato dixital no seguinte enlace: https://arcg.is/1yD5b9. O panel lateral dividido en tres seccións permite o acceso a todos os datos.

7 Esta clasificación está baseada na categorización de lugares literarios proposta no ámbito do proxecto de investigación "A proxección do lugar: Compostela no seu imaxinario xeoliterario (1844-1926). Sistemas de Información Xeográfica e Humanidades Espaciais”. Á súa vez, esta tipoloxía elaborouse a partir da clasificación de elementos espaciais empíricos que desenvolve Lynch na obra The image of the city e na categorización de lugares ficcionais que estabelece o grupo de especialistas do Instituto de Cartografía e Xeoinformación ETH Zürich ao abeiro do proxecto "Ein Literarischer Atlas Europas".

8 Esta clasificación responde á linguaxe básica da meirande parte dos Sistemas de Información Xeográfica, integrada por puntos, polígonos e liñas.

9 Esta caracterización resulta do uso de referencias indirectas e datos de lugar non necesariamente xeográficos entre outros factores. Aínda que se vai desenvolver esta cuestión de maneira pormenorizada nas seguintes liñas, parece adecuado adiantar, en termos xerais, que o espazo ficcional aparece en moitas ocasións recreado de maneira parcial, sen límites ou localizacións concretas (Piatti, 2017, p. 50). En canto a esta última afirmación, tamén convén aclarar que os espazos ficcionais "are complete as concerns the text, its story and its interests, but incomplete with regard to "our world"' (Ungern-Sternberg, 2009, pp. 238-39).

10 Ante a inexistencia doutras análises destinadas á mesma fin, aplico a tipoloxía de espazos inmapeábeis que estabelezo na miña tese de doutoramento (Rozas, 2019, pp. 204-241).

11 Esta tipoloxía ten a súa orixe nas tres clases de espazos ficcionais propostas por Reuschel e Hurni (2011, p. 296). Secasí, como no caso dos lugares inmapeábeis, o seu tratamento correspóndese co axuste e desenvolvemento definitorio destas categorías segundo aparece recollido na miña tese (Rozas, 2019, pp. 248-275).

12 Para facilitar a lectura dos mapas e a prol de estudos espaciais posteriores, sitúo este lugar, a modo de licenza cartográfica, nas coordenadas correspondentes á devandita Porta do Popolo.

13 Máis polo miúdo, entre Strandia e Inlandia parece estabelecerse un xogo etimolóxico e gobernativo de contraposición. Mentres que a primeira contén a palabra Strand -do inglés antigo strand e, á súa vez, do protoxermánico *strandō-, que significa "costa”, a segunda é susceptíbel de se dividir nos lexemas In- e -land, que significan "interior" e "terra" respectivamente. Xa que logo, o autor estaría facendo referencia a unha localización sen acceso ao mar, que se podería corresponder coa marca de Austria ou östarrîchi -literalmente "a marca do leste", é dicir, o leste de Europa, que carece de territorio marítimo. Do mesmo xeito, segundo a narración, de Inlandia procede un margrave, título correspondente aos gobernantes da Marca de Austria. En cambio, Strandia preséntase coma un ducado igual que Normandía.

14 Os criterios que permiten determinar cales son os potenciais reflexos empíricos destes emprazamentos supoñen unha adaptación dos estabelecidos por Plini, Di Franco e Salvatori (2016). Estes estudosos localizan topónimos tendo en conta as características topográficas e as circunstancias históricas dos lugares aos que aluden, así como as variantes léxicas, lingüísticas, semánticas, idiomáticas e ortográficas das denominacións.

15 Tamén se podería apuntar unha reformulación, en certa medida satírica, do nome da cidade, pois evoca o termo nervio. A verba remitiría metaforicamente ao feito de que o reflexo real da cidade de Nerbia é un dos tres puntos de peregrinación máis importantes do cristianismo á par de Roma e Xerusalén.

16 A presente análise permite desterrar consideracións coma a de Salgado (Risco, 1981, p. 7) quen defendeu, con respecto á temática da obra, que "no se percibe, sin forzar el análisis, rastro de 'lo gallego"'. Nunha liña semellante, este exame tamén posibilita matizar a clasificación desta novela que fai Soldevila (1996, p. 310) como "relato histórico [...] en que el narrador establece una referencialidad exclusiva con un modelo de mundo verosímil, pero desanclado de toda referencia a modelos de mundo real verificable". Máis acaídas semellan as observacións de Otero Pedrayo ao percibir que: "o ritmo, o ambente entre místico e satírico, a ausencia de criterios burgueses e ouxetivos, proceden dos estudos e fantasías galegas do autor" (Risco, 1981, p. 7).

Cómo citar: Rozas Arceo, A. (2021). A porta de palla ou a visión alternativa de Santiago de Compostela de Vicente Risco. Boletín Galego de Literatura, 59, “Estudos”, 1-20. DOI http://dx.doi.org/10.15304/bgl.59. 7958 